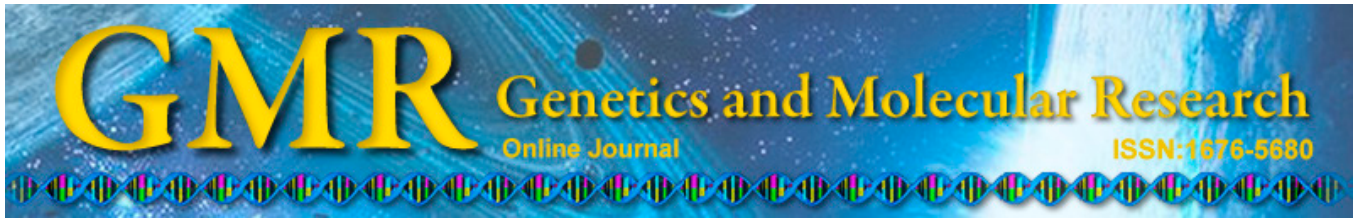

\title{
Comparative proteomic analysis reveals mite (Varroa destructor) resistance-related proteins in Eastern honeybees (Apis cerana)
}

\author{
T. Ji', F. Shen ${ }^{1}$, Z. Liu ${ }^{2}$, L. Yin ${ }^{3}$, J. Shen ${ }^{1}$, Q. Liang ${ }^{4}$ and Y.X. Luo \\ ${ }^{1}$ College of Animal Science and Technology, Yangzhou University, \\ Yangzhou, China \\ ${ }^{2}$ Shangdong Agricultural University, Shandong, China \\ ${ }^{3}$ Institute of Food Science and Technology, \\ Jiangsu Agri-Animal Husbandry Vocational College, Taizhou, China \\ ${ }^{4}$ College of Bee Science, Fujian Agriculture and Forestry University, \\ Fuzhou, China \\ ${ }^{5}$ Guangdong Entomological Institute, Guangzhou, China \\ Corresponding author: T. Ji \\ E-mail: tji@yzu.edu.cn
}

Genet. Mol. Res. 14 (3): 10103-10118 (2015)

Received December 4, 2014

Accepted May 8, 2015

Published August 21, 2015

DOI http://dx.doi.org/10.4238/2015.August.21.18

\begin{abstract}
The mite (Varroa destructor) has become the greatest threat to apiculture worldwide. As the original host of the mite, Apis cerana can effectively resist the mite. An increased understanding of the resistance mechanisms of Eastern honeybees against $V$. destructor may help researchers to protect other species against these parasites. In this study, the proteomes of 4 Apis cerana colonies were analyzed using an isobaric tag for relative and absolute quantitation technology. We determined the differences in gene and protein expression between susceptible and resistant colonies that were either unchallenged or challenged by $V$. destructor. The results showed that a total of 1532 proteins were identified. Gene Ontology enrichment analysis suggested that the transcription factors and basic metabolic and respiratory
\end{abstract}


processes were efficient and feasible factors controlling this resistance, and 12 differentially expressed proteins were identified in Venn analysis. The results were validated by quantitative polymerase chain reaction. This study may provide insight into the genetic mechanisms underlying the resistance of honeybee to mites.

Key words: Apis cerana; Differential expression; Proteome; Varroa destructor

\section{INTRODUCTION}

Varroa destructor is a parasitic mite that attacks honeybees, specifically Apis mellifera, by feeding on the hemolymph of developing and adult bees (Rosenkranz et al., 2009). $V$. destructor is also a vector and inducer of several highly pathogenic honeybee viruses that cause severe damage to bee colonies, often leading to colony death (Ball and Allen, 1988; Annoscia et al., 2012). V. destructor spread from its native host Apis cerana to A. mellifera 4 decades ago and later spread to nearly every part of the world (Griffith and Bowman, 1981; Sammataro et al., 2000). It has become the greatest threat to A. mellifera health worldwide (van Engelsdorp et al., 2008; Highfield et al., 2009; Cornman et al., 2012). A. mellifera is vulnerable to Varroa; however, the mites rarely cause serious damage to their native host $A$. cerana (Boot et al., 1997; Oldroyd, 1999). In fact, in some regions of China, it is difficult to find Varroa mites in A. cerana populations (Zhou, 2005). Natural selection for benign hostparasite interactions may have played a role in these relationships to promote the co-existence between A. cerana and Varroa (Warrit and Lekprayoon, 2011). Several factors have been implicated in Varroa resistance in A. cerana, including grooming, hygienic behavior, and differences in developmental timing (Peng et al., 1987); however, the genetic mechanisms that underlie the resistance to Varroa mites remain unclear. Resistant and susceptible lines of $A$. mellifera have previously been used in studies of gene expression and to identify resistance genes with microarrays (Navajas et al., 2008; Parker et al., 2012), and chromosomal regions that contain genes affecting specific traits by quantitative trait locus mapping (ArechavaletaVelasco et al., 2012; Guzman-Novoa et al., 2012; Tsuruda et al., 2012). However, it is difficult to compare these studies because they used different breeding lines of bees with different genetic backgrounds. Additionally, the candidate genes and quantitative trait locus could not be confirmed in other studies. Furthermore, the level of resistance to Varroa mites is likely regulated by several genes and markers, and A. cerana may possess all resistance characteristics. Rath and Drescher (1990) suggested that it is necessary to first clarify the relationship between Varroa and A. cerana before understanding the relationship between Varroa and A. mellifera. Thus, understanding the molecular mechanism of Varroa resistance in A. cerana may explain the lack of $A$. mellifera resistance to Varroa.

Previous studies have reported that $V$. destructor was present and caused visible damage in certain A. cerana colonies in the Guangdong Province (Zhou, 2005). We obtained these bees, which we designated $\mathrm{M}$ bees (i.e., mite-susceptible bees). We compared the head-specific protein expression profiles of these bees with those of common A. cerana (C) showing resistance to $V$. destructor. The isobaric tag for relative and absolute quantitation (iTRAQ) method was used to analyze the proteome of $A$. cerana workers, and we identified differences in the protein expression between $A$. cerana $\mathrm{M}$ and $\mathrm{C}$ workers, the challenged resistant colony 
$\left(\mathrm{C}^{+}\right)$, and the challenged sensitive colony $\left(\mathrm{M}^{+}\right)$. Our goal was to identify possible proteins associated with resistance to $\mathrm{V}$. destructor parasitism, which may provide insight into $\mathrm{A}$. mellifera resistance.

\section{MATERIAL AND METHODS}

\section{Honeybee colonies and Varroa challenge}

The $\mathrm{M}$ and $\mathrm{C}$ bees in this study belonged to unrelated local strains of the same $A$. cerana population, both of which were bred at the Guangdong Entomological Institute, Guangzhou, China. We selected 2 combs from an infested brood of $A$. mellifera colonies containing mature female mites in worker brood cells, both of which contained approximately equal numbers of capped worker brood cells and capped drone brood cells (Tan and Yu, 2002). The 2 combs were then introduced into the $\mathrm{C}$ and $\mathrm{M} A$. cerana colonies. After being challenged for $24 \mathrm{~h}$, infection of the $\mathrm{C}$ and $\mathrm{M}$ colonies was evaluated and nurse workers from the $2 \mathrm{~A}$. cerana colonies were collected. The challenged resistant colony $\left(\mathrm{C}^{+}\right)$and the challenged sensitive colony $\left(\mathrm{M}^{+}\right)$accepted combs with similar degrees of mite infection and similar numbers of capped cells; the unchallenged resistant colony $(\mathrm{C})$ and the unchallenged sensitive colony (M) accepted combs containing similar numbers of capped cells without mite infection.

\section{Sibling estimation by microsatellite genotyping}

To minimize the effects of intra-colonial genetic variation on gene expression, pools of full-sister workers (related by $75 \%$ due to haplodiploidy) were collected in equal numbers from the 4 colonies (Winston, 1987; Navajas et al., 2008). To identify the full sisters, 100 bees from each colony were genotyped using the Ap53 and A107 microsatellite loci (Franck et al., 1999).

\section{Protein isolation and labeling}

The pooled $(\mathrm{N}=30)$ frozen head tissues from each colony that were isolated on the same collection day were ground in liquid nitrogen, and the total protein was isolated from the freeze-dried powder after resuspension in $500 \mu \mathrm{L}$ dissolution buffer containing $1 \mathrm{mM}$ phenylmethylsulfonyl fluoride, $2 \mathrm{mM}$ EDTA, and $10 \mathrm{mM}$ dithiothreitol. The resuspended powder was incubated for $30 \mathrm{~min}$ and then sonicated for $15 \mathrm{~min}$. After centrifugation at 25,000 $\mathrm{g}$ for 20 min at $15^{\circ} \mathrm{C}$, the supernatant was collected and mixed with a solution of $10 \mathrm{mM}$ dithiothreitol for $1 \mathrm{~h}$ at $56^{\circ} \mathrm{C}$ to reduce and cleave the disulfide bonds. After centrifugation of the samples, a freshly prepared solution of $55 \mathrm{mM}$ iodoacetamide was added. The samples were then covered in foil and incubated in the dark at room temperature for $45 \mathrm{~min}$. Pre-chilled acetone was added to the protein samples at a 5:1 ratio (acetone/sample, $\mathrm{v} / \mathrm{v}$ ), and the samples were then incubated at $-20^{\circ} \mathrm{C}$ for $2 \mathrm{~h}$. After centrifugation at $25,000 \mathrm{~g}$ for $20 \mathrm{~min}$, the precipitated pellets were resuspended in $60 \mu \mathrm{L}$ solution containing $7 \mathrm{M}$ urea and $500 \mathrm{mM}$ tetraethylammonium bicarbonate, $\mathrm{pH} 8.5$, and sonicated for $15 \mathrm{~min}$. The supernatants were then isolated after centrifugation at 25,000 $\mathrm{g}$ for $20 \mathrm{~min}$. Total protein concentration was measured using the Bradford method, and the protein integrity was assessed by $12 \%$ sodium dodecyl sulfatepolyacrylamide gel electrophoresis (Figure 1). 


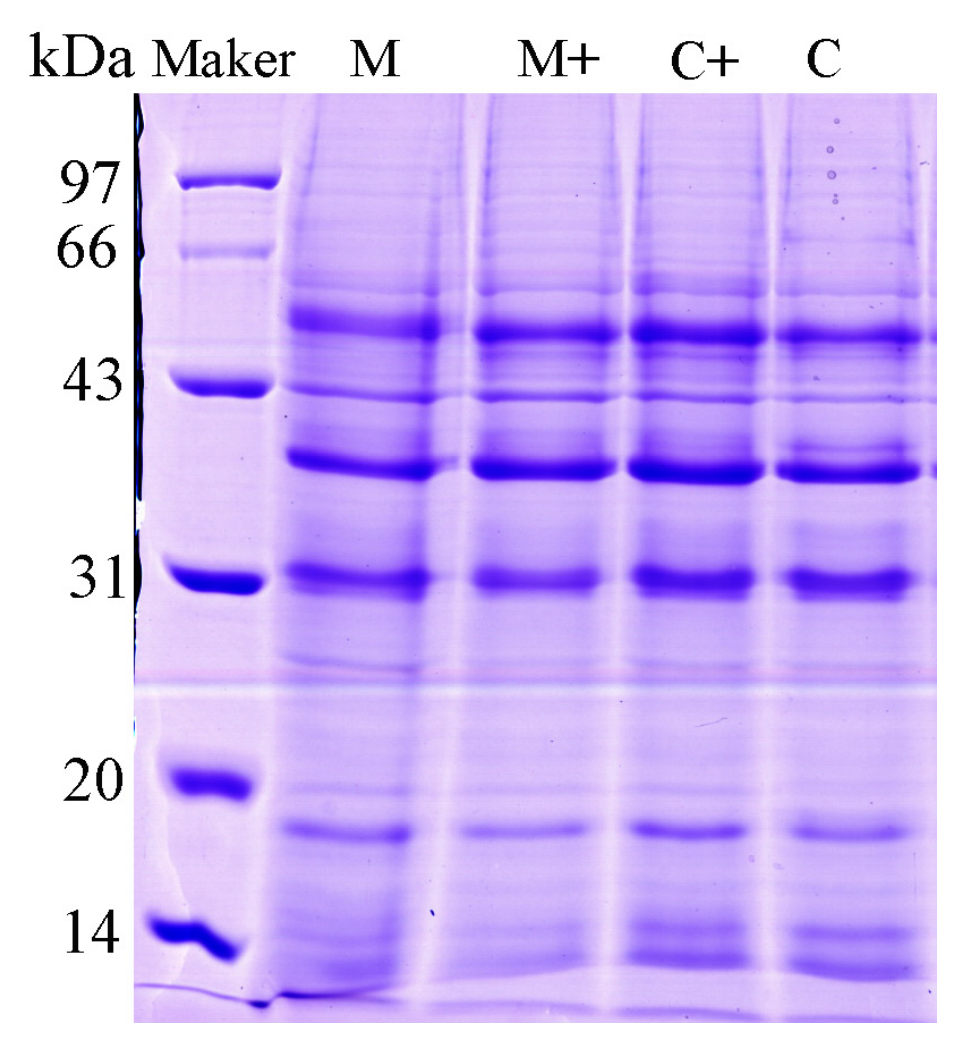

Figure 1. 1-D polyacrylamide gel electrophoresis (12\%) of proteins isolated from the head of Apis cerana.

An aliquot of $100 \mu \mathrm{g}$ of each sample was mixed with trypsin at a final ratio of 1:20 (trypsin/sample) and then incubated overnight at $37^{\circ} \mathrm{C}$. The peptides were then dried using a centrifugal vacuum concentrator, denatured with $2 \%$ sodium dodecyl sulfate, reduced with reducing reagent, treated with iodoacetamide to block disulfide bond formation, and reconstituted in $0.5 \mathrm{M}$ tetraethylammonium bicarbonate. The proteins were then labeled with the 8-plex iTRAQ reagents according to the manufacturer instructions (Applied Biosystems, Foster City, CA, USA). Samples of $\mathrm{C}^{+}, \mathrm{M}^{+}, \mathrm{C}$, and $\mathrm{M}$ were labeled with the 116-, 117-, 118-, and 119-tagged iTRAQ reagents, respectively. The labeled samples were mixed, incubated at room temperature for $2 \mathrm{~h}$, pooled, and then dried by vacuum centrifugation.

Next, the combined labeled samples were reconstituted with $4 \mathrm{~mL}$ buffer A $(10 \mathrm{mM}$ $\mathrm{KH}_{2} \mathrm{PO}_{4}$ in $25 \% \mathrm{ACN}, \mathrm{pH} 2.6$ ) and fractionated using a LC-20AB high-performance liquid chromatography system (Shimadzu, Kyoto, Japan) with a 4.6 x $250 \mathrm{~mm}$ Ultremex strong cation exchange column (Phenomenex Inc., Torrance, CA, USA). Strong cation exchange separation was performed at a flow rate of $1 \mathrm{~mL} / \mathrm{min}$ using elution buffer A for $10 \mathrm{~min}$, followed by a linear gradient of $5-35 \%$ buffer $\mathrm{B}\left(25 \mathrm{mM} \mathrm{NaH}_{2} \mathrm{PO}_{4}, 1 \mathrm{M} \mathrm{KCl}\right.$ in $\left.25 \% \mathrm{ACN}, \mathrm{pH} 2.7\right)$ for $11 \mathrm{~min}$ and $35-80 \%$ buffer $\mathrm{B}$ for $1 \mathrm{~min}$. The eluted fractions were monitored by measuring the absorbance at $214 \mathrm{~nm}$, after which they were desalted using a Strata X C18 column (Phenomenex) and vacuum-dried. 


\section{Liquid chromatography (LC)-electrospray ionization (ESI)-mass spectrometry (MS)/MS analysis with TripleTOF 5600}

LC-ESI-MS/MS analysis was performed on a nanoACQUITY system (Waters, Milford, MA, USA) connected to a TripleTOF 5600 (AB SCIEX, Concord, ON, Canada). The peptide mixture was loaded onto a C18 BEH column (5 $\mu \mathrm{m}$ x $180 \mu \mathrm{m} \times 20 \mathrm{~mm}$, Waters) and separated using solvent $\mathrm{A}(2 \% \mathrm{ACN}, 0.1 \%$ formic acid, v/v) for $15 \mathrm{~min}$ at a flow rate of $2 \mu \mathrm{L} / \mathrm{min}$. The peptides were eluted for 1 min with $5 \%$ solvent B ( $98 \% \mathrm{ACN}, 0.1 \%$ formic acid) at $300 \mathrm{~nL} / \mathrm{min}$, followed by a 40 -min gradient of 5-35\% solvent $\mathrm{B}$ at $300 \mathrm{~nL} / \mathrm{min}$, a 5 -min linear gradient to $80 \%$ solvent B that was held for $5 \mathrm{~min}$, and finally, a return to $2 \%$ solvent B over $1 \mathrm{~min}$.

The peptides were subjected to nanoelectrospray ionization, followed by MS/MS in a TripleTOF 5600 that was coupled in line to the high-performance liquid chromatography system in reflection mode with specific applied parameters of electrospray voltage $(2.5 \mathrm{kV})$ and nitrogen pressure ( $30 \mathrm{psi} ; 14.5 \mathrm{psi} \approx 1$ bar). The analytical cycle consisted of a MS survey scan (400-2000 m/z), followed by $5 \mathrm{~s}$ of MS/MS scans (50-2000) of the 5 most abundant peaks (i.e., precursor ions) selected from the initial MS survey scan. Precursor ion selection was based on ion intensity (peptide signal intensity greater than 25 counts/s) and charge state $\left(2^{+}\right.$to $\left.5^{+}\right)$. After the ions were fragmented in the MS/MS scan, one repetition was allowed before a dynamic exclusion period of $120 \mathrm{~s}$. Intact peptides were detected at a resolution of no less than 30,000 full width half maximum with $10 \mathrm{~ms}$ of accumulation time.

\section{Database search and quantification}

The original MS/MS data file (*.wiff) was converted to the *.mgf format and then searched using the Mascot software version 2.3.02 (Matrix Science, London, UK) with a database that had been created from the transcriptomic coding sequence FASTA database (GEO accession No. GSE47136) by 6-frame translation (34702 sequences). For protein identification and quantification, the search parameters were set to a fragment mass tolerance (monoisotopic mass) of $0.1 \mathrm{Da}$ and a peptide mass tolerance of $0.05 \mathrm{Da}$. The carbamidomethylation of cysteine was considered a fixed modification, and the conversion of $\mathrm{N}$-terminal glutamine to pyroglutamic acid and the oxidation of methionine were considered variable modifications. The instrument type was set to "default", and the enzyme specificity of trypsin was set to allow up to 1 missed cleavage. A mass accuracy of 2 parts per million was used in this analysis, which is typical for the latest generation of benchtop time-of-flight mass spectrometers.

All peptides identified had ion scores that were greater than the Mascot peptide identity threshold. The presence of at least 1 unique peptide match with a significance threshold of $95 \%$ confidence was required to proceed to protein quantification. Proteins quantified with at least a 2-fold change (average iTRAQ ratio $>2$-fold or $<0.5$-fold) and a 2 -tailed $\mathrm{P}$ value less than 0.05 was considered to indicate a differentially expressed protein (DEP).

\section{Bioinformatics and annotations}

To determine the biological and functional properties of the peptides and identify candidate biomarkers, DEP sequences were retrieved from the UniProt database and mapped with Gene Ontology (GO) Terms (http://www.geneontology.org) using a local BLAST against the FTP resource (ftp.geneontology.org/pub/go). Functional category analysis was performed us- 
ing protein2go and go2protein. The Clusters of Orthologous Groups protein database (http:// www.ncbi.nlm.nih.gov/COG/) was employed for functional annotation of genes from new genomes and to investigate genome evolution. The KEGG database (http://www.genome.jp/ kegg/pathway.html) and GO enrichment analysis were also used.

\section{Validation by quantitative reverse transcription-polymerase chain reaction (qRT-PCR)}

The expression levels of genes corresponding to 30 commonly expressed DEPs were examined by RT-PCR with 3 biological replicates. Gene-specific primers (Table 1) were designed using Primer-BLAST online and the Oligo 7 software, ensuring that the primer pairs flanked an exon-exon boundary to allow differentiation of fragments amplified from genomic DNA. Transcript analysis during RJ secretion revealed mixed results with 2 sets of information. The reactions were performed using the ABI 7500 system with SYBR Green. The qRT-PCR data were expressed relative to the expression of $\beta$-actin using the $2^{-\Delta \Delta C t}$ method, an independent-sample $t$-test available in the SPSS software version 16.0 (SPSS Inc., Chicago, IL, USA). Pearson correlation was used to access the relationship between transcript and protein expression values (Sun et al., 2013). A P value of 0.01 was used to determine statistical significance (Fleige and Pfaffl, 2006).

\section{Table 1. Primers for relative quantitative real-time PCR (qPCR).}

\begin{tabular}{|c|c|c|c|}
\hline Gene ID & Gene & Sequence & Size \\
\hline \multirow[t]{2}{*}{ CL4092.Contig2-All } & Obp4 & ACACAGGCTTCGAAACATCC & 106 \\
\hline & & TTCTATGCTCGCAAAAAGCA & \\
\hline \multirow{2}{*}{ unigene27402-All } & Obpl3 & TTTTCAGCATGCAATCAACG & 107 \\
\hline & & CGCCGAAGAAAATGGTATTG & \\
\hline \multirow[t]{2}{*}{ CL158.Contig2-All } & Obpl7 & TGTTGAGCAGTGCCAATTTC & 102 \\
\hline & & TGCTATTTGCGTTTGCGTTA & \\
\hline \multirow[t]{2}{*}{ CL7434.Contig2-All } & Obpls & TGGCTATGACGATGGTGGAA & 118 \\
\hline & & AGCATCAGAGATAGCCGAACA & \\
\hline \multirow[t]{2}{*}{ unigene $30062-\mathrm{A} 11$} & Mklb-l & GGGGAATCTTAAAGGCGAAG & 120 \\
\hline & & TGCCAAGCACTACACCAAAA & \\
\hline \multirow{2}{*}{ CL6237.Contig2-All } & $T p n C$ & GGCTGCACACTCTCTTCCTC & 120 \\
\hline & & TCCCAATCCGAATGAATGAT & \\
\hline \multirow{2}{*}{ CL3528.Contig5-All } & $\mathrm{Ca}^{2+}$-ATPase & ACTGTTTTGCAATGGCCGTC & 230 \\
\hline & & AATCGCAAAGTGCAAGCAGG & \\
\hline \multirow[t]{2}{*}{ CL7215.Contig3-All } & $D S C A M$ & GGTTGAGCACATCGCAACAT & 118 \\
\hline & & AAAAATCGACAGCGAGCAGC & \\
\hline \multirow[t]{2}{*}{ unigene30262-All } & $C R E B 2$ & ACAGCAATCCGTAAGGTGGG & 127 \\
\hline & & GGCGTGTCGAGGATTCAACT & \\
\hline \multirow[t]{2}{*}{ unigene28124-All } & $R$ & GAGATGGAAGCCTCTCCACG & 170 \\
\hline & & GCAATCGGCCCAGTATGAGA & \\
\hline \multirow[t]{2}{*}{ unigene561-All } & $P K A$ & CCGAGTGTGAAAAATTGCGGT & 166 \\
\hline & & CGTCGATGTTGGCCCTATGA & \\
\hline \multirow[t]{2}{*}{ CL214.Contigl -All } & $P K G$ & CTCGCATTCTCCACCGATCT & 168 \\
\hline & & TCCACCACCACCCGATGATA & \\
\hline \multirow[t]{2}{*}{ unigene25373-All } & synapsin $(S y n)$ & ATGTTCGTTGTTCCGTAGGC & 141 \\
\hline & & TTATCATTCTTGCGGCGACTA & \\
\hline \multirow[t]{2}{*}{ unigene24442-All } & $I G F n 3-2$ & ACGTGTCGACTGAAGATCGG & 179 \\
\hline & & ACCGTGTACTTGATGTGGCT & \\
\hline \multirow[t]{2}{*}{ CL9070.Contigl-All } & Apidermin-like & GCTCCTCTCCAAAGTGGCAT & 111 \\
\hline & & CGCTAGTACCTCCATCGCTC & \\
\hline \multirow[t]{2}{*}{$\beta$-actin } & & TGCCAACACTGTCCTTTCTG & 155 \\
\hline & & AATACAAACTGGTGGAAGCTACAGG & \\
\hline
\end{tabular}




\section{RESULTS}

\section{Proteomic analysis}

The iTRAQ method was applied for proteomic analysis of the challenged mite-resistant colony $\left(\mathrm{C}^{+}\right)$, challenged mite-sensitive colony $\left(\mathrm{M}^{+}\right)$, unchallenged mite-resistant colony $(\mathrm{C})$, and challenged mite-sensitive colony $(\mathrm{M})$. A total of 1532 proteins were identified. When the expression level of a protein showed a $>2$-fold or $<0.5$-fold change in abundance, the protein was considered to be differentially expressed. A total of 72 proteins were differentially expressed in $\mathrm{C}^{+} v s \mathrm{M}^{+}$, with 31 down-regulated proteins and 41 up-regulated proteins in $\mathrm{C}^{+}$. A total of 154 proteins were differentially expressed in $\mathrm{C} v s \mathrm{M}$, with 82 down-regulated proteins and 72 up-regulated proteins in C. A total of 202 unigenes were differentially expressed in $\mathrm{C}^{+}$ vs $\mathrm{M}^{+}$, with 81 down-regulated unigenes and 121 up-regulated unigenes in $\mathrm{C}^{+}$. A total of 161 unigenes were differentially expressed in $\mathrm{M}^{+} v s \mathrm{M}$, with 94 down-regulated unigenes and 67 up-regulated unigenes in $\mathrm{M}^{+}$(Figure 2).
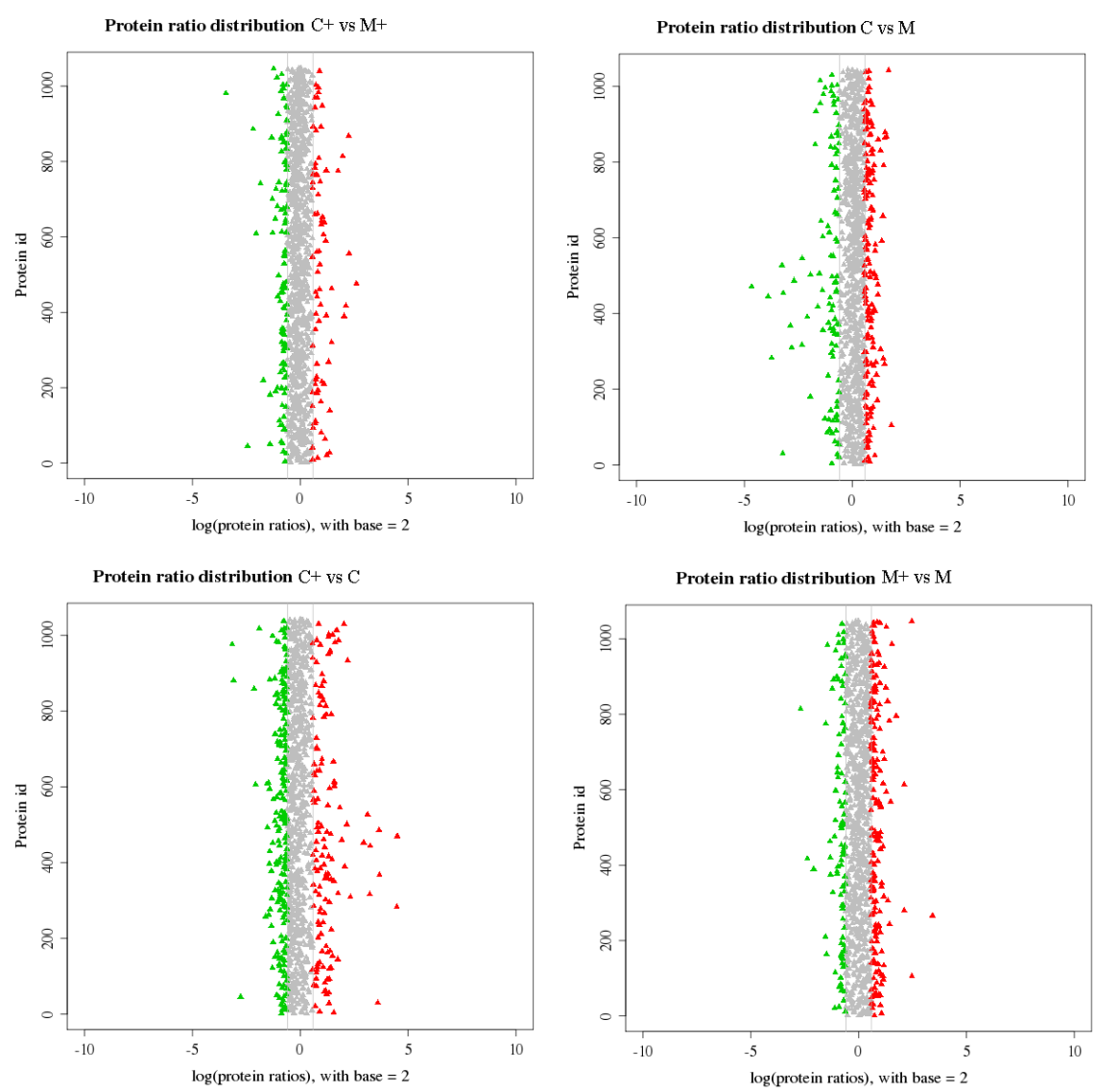

Figure 2. Protein ratio distributions. The $x$-axis indicates the fold-change (ratios) of proteins based on the logarithm with base 2 . The $y$-axis indicates the protein. Red and green spot represent significantly up- and down-regulated proteins, and gray spots indicate no significant difference. 


\section{Enrichment analysis of GO function of DEPs}

To determine whether the DEPs were enriched in certain functional groups, enrichment analysis was conducted using Blast2GO. A total of 36 different proteins were enriched in $129 \mathrm{GO}$ biological process entries in $\mathrm{C}^{+} v s \mathrm{M}^{+}$(Figure 3); 4 of these proteins were significant. The most significant enrichment was for a defensive response ( 4 different proteins, accounting for $11.1 \%$ of the total), followed by variable shear (5.6\%) and mRNA apoptosis (5.6\%). The other significantly enriched proteins were related to stress response (13.9\%).

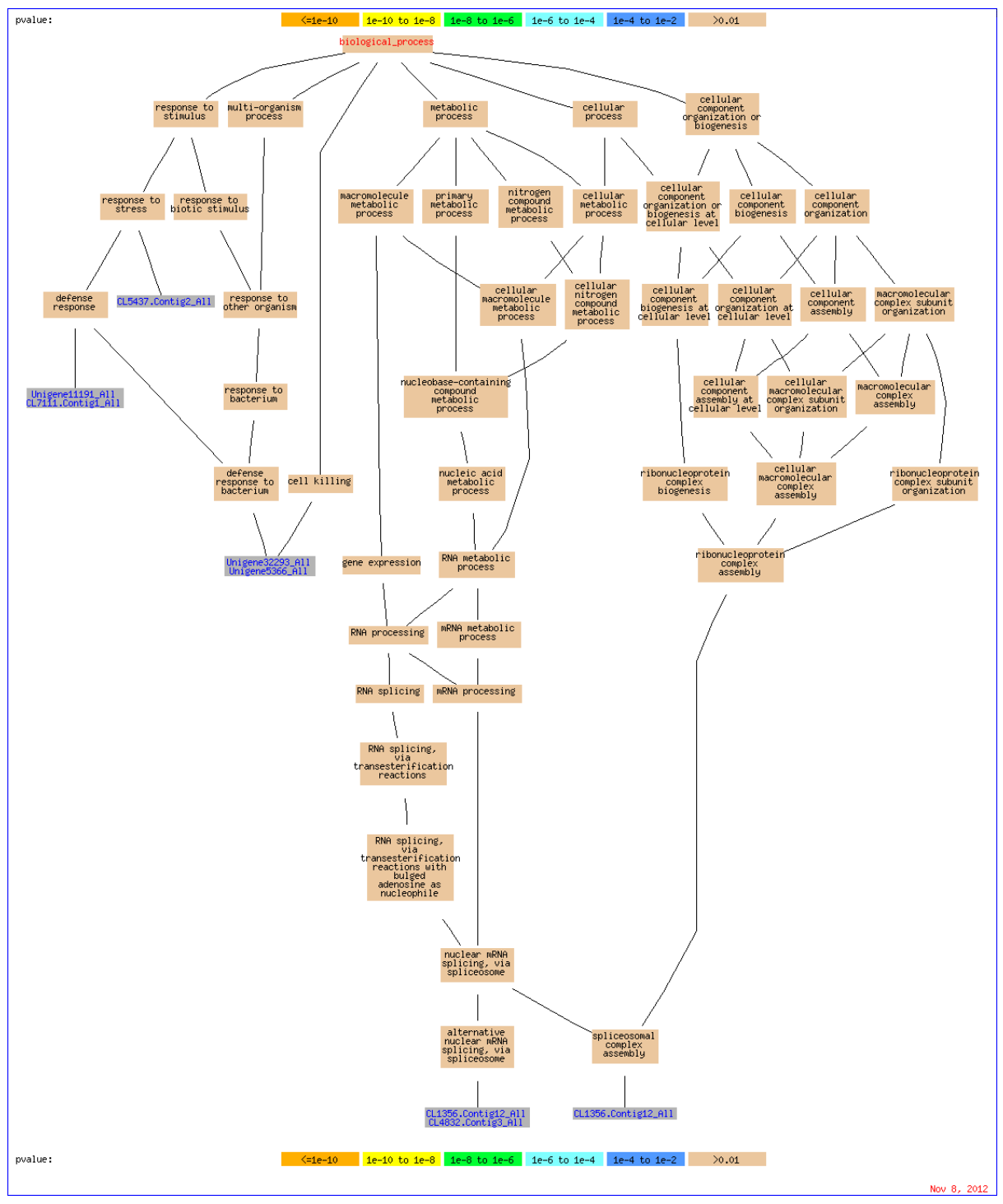

Figure 3. GO biological process enrichment analysis of differentially expressed proteins of Apis cerana $\left(\mathrm{C}^{+}\right.$vs $\left.\mathrm{M}^{+}\right)$. 
In $\mathrm{C} v s \mathrm{M}$ (Figure 4), a total of 79 different proteins were enriched in $156 \mathrm{GO}$ biological process entries, of which 18 processes were significant. The processes were mainly associated with metabolic, respiratory, and other life activities. Cellular respiration was the most significant $(11.4 \%)$, followed by organic compound oxidation capacity $(5.6 \%)$, cell respiration (7.6\%), oxidation processes $(11.4 \%)$, precursor metabolism and energy production $(12.7 \%)$, and glucose metabolism $(7.6 \%)$.

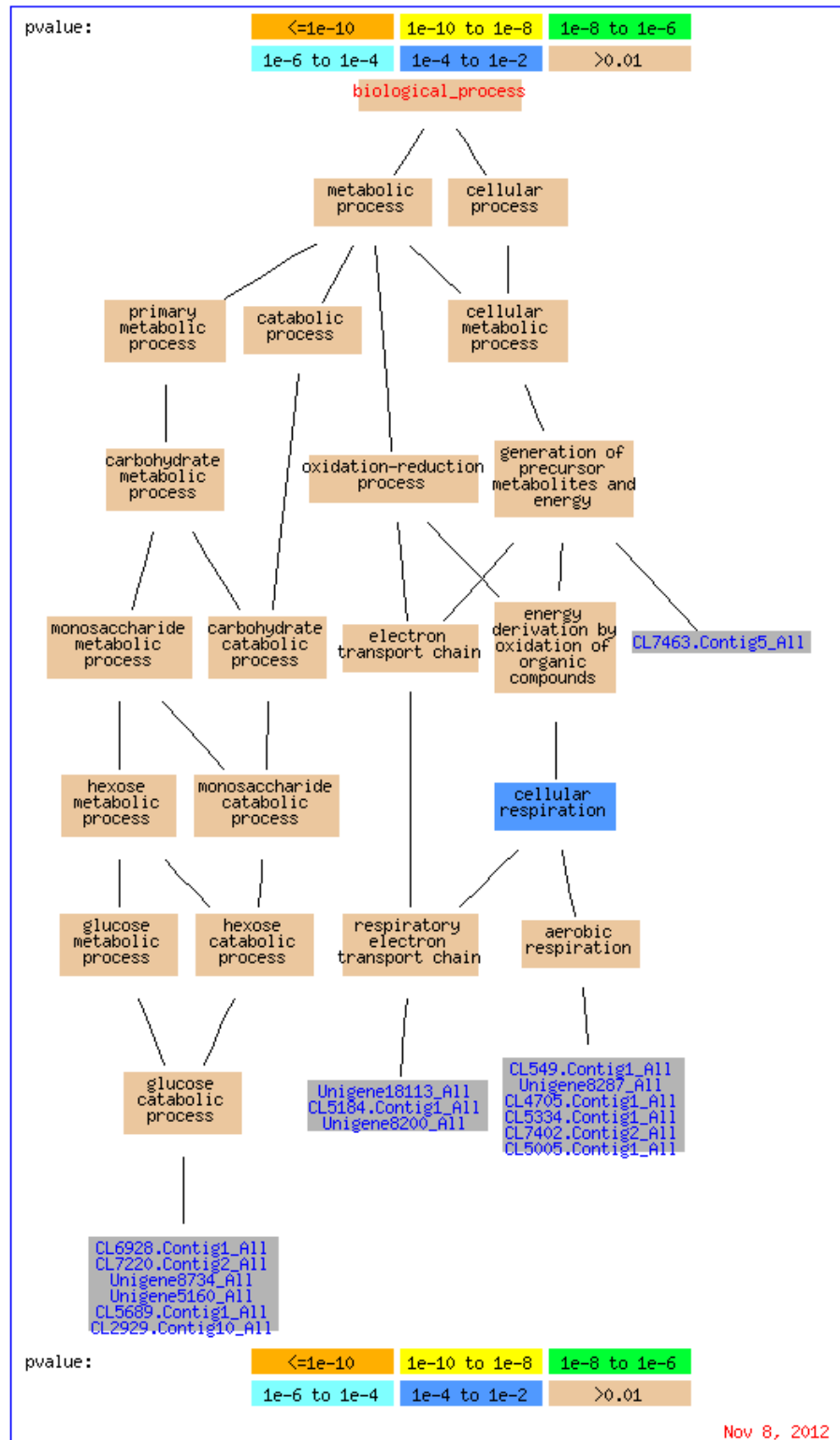

Figure 4. GO biological process enrichment analysis of differentially expressed proteins of Apis cerana (C vs $\mathrm{M})$. 


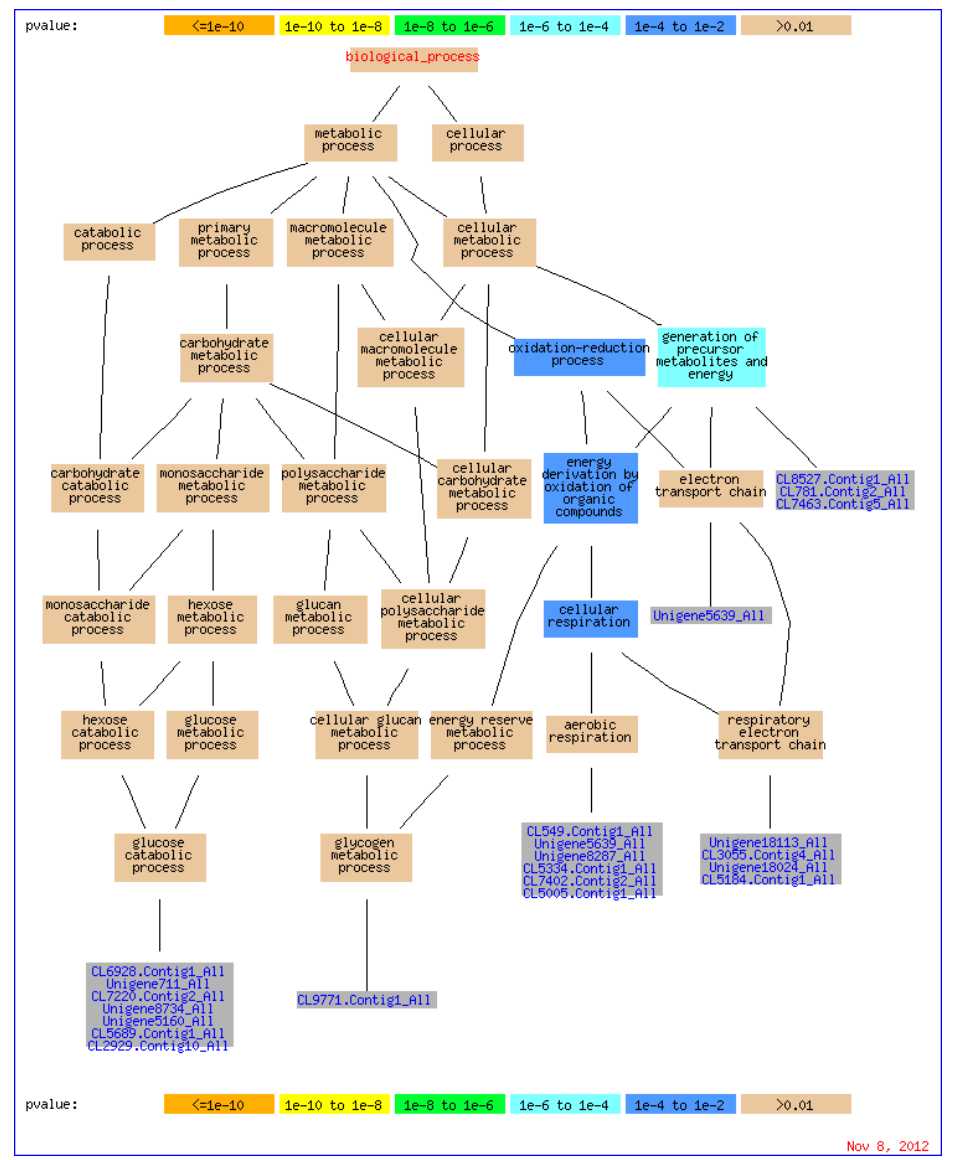

Figure 5. GO biological process enrichment analysis of differentially expressed proteins of Apis cerana $\left(\mathrm{C}^{+}\right.$vs $\left.\mathrm{C}\right)$.

In $\mathrm{M}^{+}$vs $\mathrm{M}$ (Figure 6), a total of 85 different proteins were enriched in $99 \mathrm{GO}$ biological process entries, of which 36 processes were significant. The processes were mainly related to the biosynthesis of adenosine triphosphate, nucleotide biosynthesis, glutamic acid metabolism, and normal life activities, such as ion transport. Ion transport was the most significant process (11.8\%), followed by hydrogen transfer (7.1\%), defense response (4.7\%), and transmembrane transport (4.7\%).

\section{Enrichment analysis of pathways}

We conducted an enrichment analysis of the 89 enriched proteomic molecular pathways of all DEPs of $\mathrm{C}^{+} v s \mathrm{M}^{+}$. Only one significant enrichment, sphingolipid metabolism (ko00600), was observed, which contained only a single DEP (CL9848. Contig1_All).

In $\mathrm{C}$ vs M, 119 different proteins were enriched in 119 pathways, of which 17 pathways were significantly enriched. The most significantly enriched pathway was the metabolic pathway (42.86\%), followed by oxidative phosphorylation (15.97\%) (Table 2). 


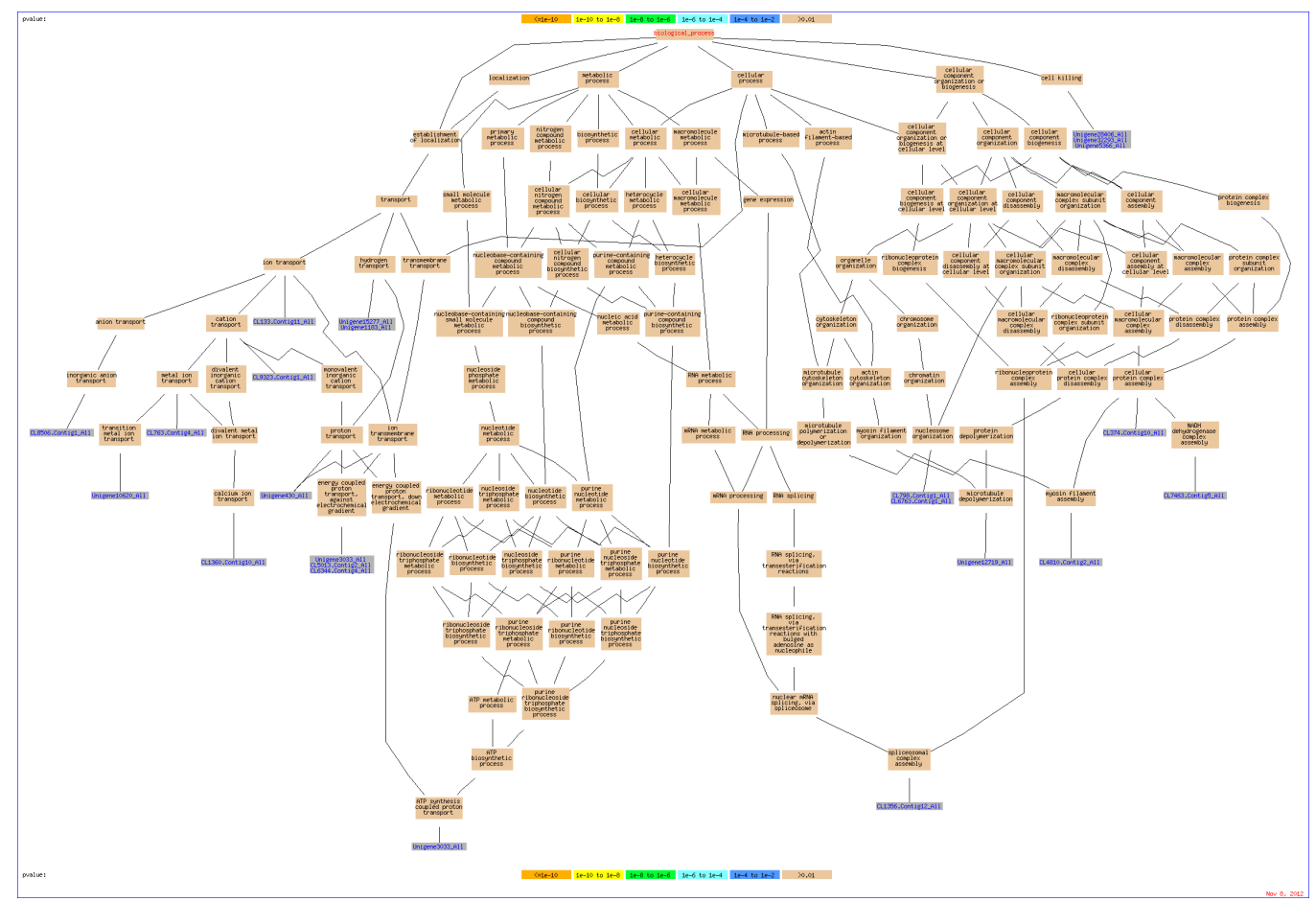

Figure 6. GO biological process enrichment analysis of differentially expressed proteins of Apis cerana $\left(\mathrm{M}^{+} v s \mathrm{M}\right)$.

Table 2. Significant pathway enrichment of differentially expressed proteins (C vs M).

\begin{tabular}{lccc}
\hline Pathway & Number of different proteins (119) & P value & Pathway ID \\
\hline Metabolic pathways & $51(42.86 \%)$ & $4.54 \mathrm{E}-08$ & ko01100 \\
Oxidative phosphorylation & $19(15.97 \%)$ & $1.60 \mathrm{E}-06$ & ko00190 \\
Parkinson's disease & $17(14.29 \%)$ & $1.93 \mathrm{E}-06$ & $\mathrm{k} 005012$ \\
Citrate cycle (TCA cycle) & $11(9.24 \%)$ & $1.69 \mathrm{E}-05$ & $\mathrm{k} 000020$ \\
Huntington's disease & $19(15.97 \%)$ & $2.06 \mathrm{E}-05$ & $\mathrm{k} 005016$ \\
Biosynthesis of secondary metabolites & $24(20.17 \%)$ & $2.51 \mathrm{E}-05$ & $\mathrm{k} 001110$ \\
Alzheimer's disease & $20(16.81 \%)$ & $5.03 \mathrm{E}-05$ & $\mathrm{k} 005010$ \\
Microbial metabolism in diverse environments & $20(16.81 \%)$ & 0.000117 & $\mathrm{k} 01120$ \\
Glycolysis/gluconeogenesis & $10(8.4 \%)$ & 0.001411 & $\mathrm{k} 000010$ \\
Betalain biosynthesis & $3(2.52 \%)$ & 0.001411 & $\mathrm{k} 000965$ \\
Isoquinoline alkaloid biosynthesis & $3(2.52 \%)$ & 0.005939 & $\mathrm{k} 000950$ \\
Cardiac muscle contraction & $7(5.88 \%)$ & 0.006991 & $\mathrm{k} 004260$ \\
Galactose metabolism & $5(4.2 \%)$ & 0.011875 & $\mathrm{k} 00052$ \\
Riboflavin metabolism & $3(2.52 \%)$ & 0.014664 & $\mathrm{k} 000740$ \\
Starch and sucrose metabolism & $5(4.2 \%)$ & 0.017288 & $\mathrm{k} 00500$ \\
Ribosome & $10(8.4 \%)$ & 0.035206 & $\mathrm{k} 03010$ \\
Fatty acid biosynthesis & $2(1.68 \%)$ & $\mathrm{k} 00061$ \\
\hline
\end{tabular}

In $\mathrm{C}^{+}$vs $\mathrm{C}, 137$ different proteins were enriched in 99 pathways, of which 14 pathways were significantly enriched. The most significantly enriched pathway was Parkinson's disease (18.98\%), followed by Huntington's disease (20.44\%) (Table 3). 
Table 3. Significant pathway enrichment of differentially expressed proteins $\left(\mathrm{C}^{+} v s \mathrm{C}\right)$.

\begin{tabular}{|c|c|c|c|}
\hline Pathway & Number of different proteins & $P$ value & Pathway ID \\
\hline Parkinson's disease & $26(18.98 \%)$ & $3.02 \mathrm{E}-13$ & ko05012 \\
\hline Huntington's disease & $28(20.44 \%)$ & $9.80 \mathrm{E}-11$ & ko05016 \\
\hline Alzheimer's disease & $29(21.17 \%)$ & $3.73 \mathrm{E}-10$ & ko05010 \\
\hline Oxidative phosphorylation & $25(18.25 \%)$ & $6.10 \mathrm{E}-10$ & ko00190 \\
\hline Citrate cycle (TCA cycle) & $13(9.49 \%)$ & $6.48 \mathrm{E}-07$ & ko00020 \\
\hline Metabolic pathways & $49(35.77 \%)$ & $5.42 \mathrm{E}-05$ & ko01100 \\
\hline Glycolysis/gluconeogenesis & $10(7.3 \%)$ & 0.000394 & ko00010 \\
\hline Biosynthesis of secondary metabolites & $23(16.79 \%)$ & 0.000657 & ko01110 \\
\hline Microbial metabolism in diverse environments & $19(13.87 \%)$ & 0.001161 & ko01120 \\
\hline Cardiac muscle contraction & $8(5.84 \%)$ & 0.0031 & ko04260 \\
\hline RIG-I-like receptor signaling pathway & $2(1.46 \%)$ & 0.01682 & ko04622 \\
\hline Phototransduction & $5(3.65 \%)$ & 0.04592 & ko04744 \\
\hline Betalain biosynthesis & $2(1.46 \%)$ & 0.046138 & ko00965 \\
\hline Isoquinoline alkaloid biosynthesis & $2(1.46 \%)$ & 0.046138 & ko00950 \\
\hline
\end{tabular}

In $\mathrm{M}^{+}$vs $\mathrm{M}, 112$ different proteins were enriched in 116 pathways, of which 22 pathways were significantly enriched. The most significantly enriched pathway was oxidative phosphorylation (16.96\%), followed by Parkinson's disease (14.29\%) (Table 4).

Table 4. Significant pathway enrichment of differentially expressed proteins $\left(\mathrm{M}^{+} v s \mathrm{M}\right)$.

\begin{tabular}{|c|c|c|c|}
\hline Pathway & Number of different proteins (112) & $P$ value & Pathway ID \\
\hline Oxidative phosphorylation & $19(16.96 \%)$ & $5.85 \mathrm{E}-07$ & ko00190 \\
\hline Parkinson's disease & $16(14.29 \%)$ & $4.40 \mathrm{E}-06$ & ko05012 \\
\hline Huntington's disease & $17(15.18 \%)$ & 0.000108 & ko05016 \\
\hline Alzheimer's disease & $18(16.07 \%)$ & 0.000135 & ko05010 \\
\hline Metabolic pathways & $39(34.82 \%)$ & 0.000697 & ko01100 \\
\hline Mineral absorption & $3(2.68 \%)$ & 0.001175 & ko04978 \\
\hline Collecting duct acid secretion & $4(3.57 \%)$ & 0.006062 & ko04966 \\
\hline Citrate cycle (TCA cycle) & $7(6.25 \%)$ & 0.007379 & ko00020 \\
\hline Vibrio cholerae infection & $6(5.36 \%)$ & 0.01079 & ko05110 \\
\hline Phagosome & $8(7.14 \%)$ & 0.012371 & ko04145 \\
\hline Rheumatoid arthritis & $4(3.57 \%)$ & 0.015352 & ko05323 \\
\hline Nitrogen metabolism & $3(2.68 \%)$ & 0.018444 & ko00910 \\
\hline Proximal tubule bicarbonate reclamation & $3(2.68 \%)$ & 0.018444 & ko04964 \\
\hline Viral myocarditis & $5(4.46 \%)$ & 0.020834 & ko05416 \\
\hline Arrhythmogenic right ventricular cardiomyopathy (ARVC) & $4(3.57 \%)$ & 0.022175 & ko05412 \\
\hline Adherens junction & $5(4.46 \%)$ & 0.027064 & ko04520 \\
\hline Epithelial cell signaling in Helicobacter pylori infection & $4(3.57 \%)$ & 0.030585 & ko05120 \\
\hline Betalain biosynthesis & $2(1.79 \%)$ & 0.031319 & ko00965 \\
\hline Isoquinoline alkaloid biosynthesis & $2(1.79 \%)$ & 0.031319 & ko00950 \\
\hline Synthesis and degradation of ketone bodies & $2(1.79 \%)$ & 0.031319 & ko00072 \\
\hline Gastric acid secretion & $6(5.36 \%)$ & 0.041394 & ko04971 \\
\hline Phototransduction-fly & $6(5.36 \%)$ & 0.049282 & ko04745 \\
\hline
\end{tabular}

\section{Venn analysis of DEPs}

In this experiment, there were 4 groups of DEPs, the $\mathrm{C}^{+}$vs $\mathrm{M}^{+}, \mathrm{C} v s \mathrm{M}, \mathrm{C}^{+}$vs $\mathrm{C}$, and $\mathrm{M}^{+}$ $v s \mathrm{M}$ groups. A Venn analysis of these 4 DEP groups is shown in Figure 7. A total of 14 DEPs were shared by the $\mathrm{C}^{+} v s \mathrm{M}^{+}$and $\mathrm{C} v s \mathrm{M}$ groups; 58 DEPs were unique to $\mathrm{C}^{+} v_{s} \mathrm{M}^{+}$, whereas 140 DEPs were unique to $\mathrm{C} v s \mathrm{M}$. The 14 shared DEPs may have resulted from the different genetic backgrounds of the 2 colonies, and the unique genes for $\mathrm{C}^{+} v s \mathrm{M}^{+}$may be related to mite resistance. A total of 53 DEPs were shared by the $\mathrm{C}^{+} v_{s} \mathrm{C}_{\text {and }} \mathrm{M}^{+}$vs $\mathrm{M}$ groups; $148 \mathrm{DEPs}$ were unique to $\mathrm{C}^{+} v_{s} \mathrm{C}$, whereas $107 \mathrm{DEPs}$ were unique to $\mathrm{M}^{+}$vs $\mathrm{M}$. The unique genes for $\mathrm{C}^{+}$vs $\mathrm{C}$ may 
be related to mite resistance and should be investigated further. According to the above analysis, 12 differentially expressed proteins in proteins were associated with mite resistance, including CL8968.Contig2_All (60S acidic ribosomal protein P2), CL3897.Contig1_All (60S ribosomal protein L12), unigene10550_All (protein disulfide-isomerase), unigene8201_All (uncharacterized protein LOC100867799), CL9191.Contig1_All (hypothetical protein LOC550914 [Apis mellifera]), CL1814.Contig1_All (vitellogenin precursor), CL3959.Contig1_All (endocuticle structural glycoprotein SgAbd-2-like), CL6194.Contig4_All [hypothetical protein LOC411622 (Apis mellifera)], CL4832.Contig3_All [hypothetical protein LOC552027 (Apis mellifera)], unigene27402_All [odorant-binding protein 13 precursor (Apis mellifera)], unigene10882_All (polyadenylate-binding protein 1-like), and CL6237.Contig1_All (troponin C type IIb).

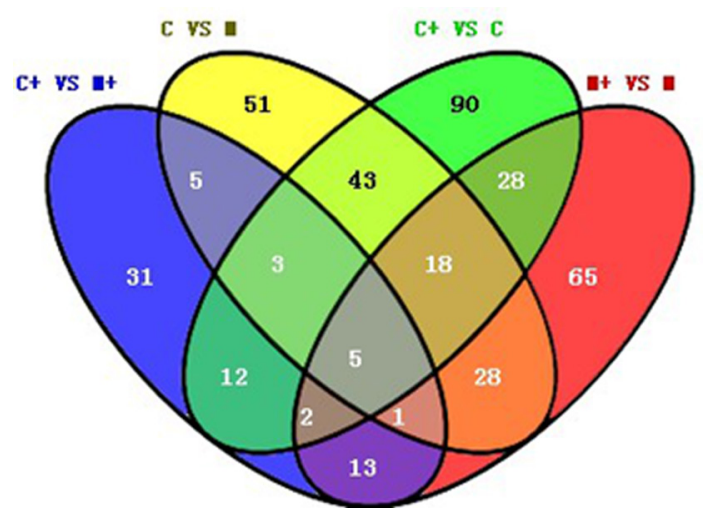

Figure 7. Venn diagram of differentially expressed proteins among the 4 groups compared. The numbers denote the amount of proteins expressed in each class.

\section{Relative qPCR analysis}

The expression values of genes for the DEPs were examined by qPCR. The results showed consistent expression patterns with the findings of proteomes analysis (Figure 8).

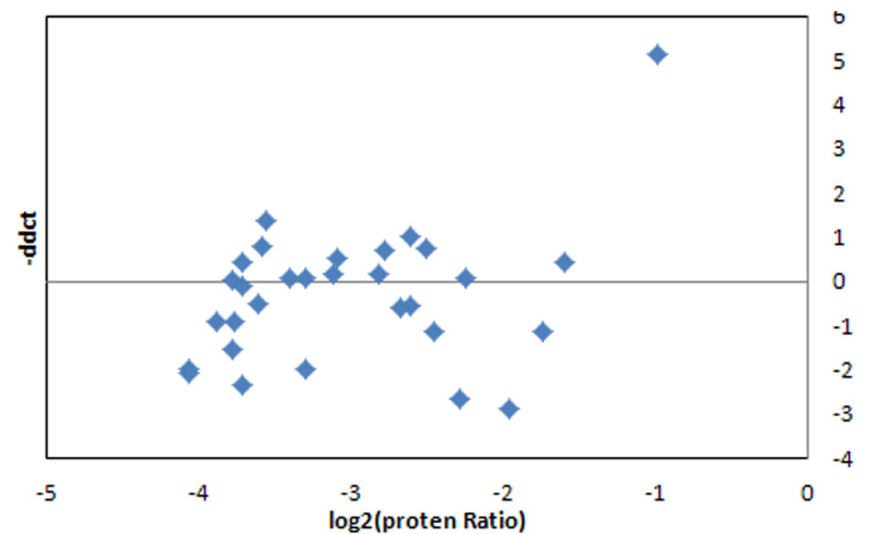

Figure 8. Correlation between the expression levels of 30 proteins and their corresponding gene transcripts. The qPCR results revealed better correlation with $r=0.423, \mathrm{P}=0.20$. The fold-change (ratios) of proteins and transcripts were based on the logarithm with base 2 . 


\section{DISCUSSION}

A total of 1532 proteins were identified in this study using iTRAQ technology. The most significantly enriched process related to mite resistance was the defense response, followed by mRNA variable shear, cell apoptosis, and stress response. These results suggest that when accompanied by variable shear, the resistant and sensitive colonies exhibited different responses when challenged by the Varroa mite. $\mathrm{In}^{+} v_{s} \mathrm{C}$, enrichment analysis of the DEPs showed that the most significantly enriched GO biological processes were the defense response and mRNA shear, suggesting that a series of responses occurs in the resistant colony when challenged by the Varroa mite. In C vs M, a total of 79 DEPs were enriched in 156 biological processes, of which 18 processes were significantly enriched. These processes primarily consisted of metabolic, respiratory, and other processes related to life activities, suggesting that different metabolic processes exist between resistant and sensitive colonies. In $\mathrm{M}^{+} v s \mathrm{M}$, a total of 85 DEPs were enriched to 99 GO biological processes, of which 36 processes were significantly enriched. These processes were primarily associated with the biosynthesis of adenosine triphosphate, nucleotide biosynthesis, glutamic acid metabolism, ion transport, defense response, and transmembrane transport, indicating that activities in the sensitive colony were affected when challenged by the Varroa mite.

A total of 12 DEPs were correlated with $V$. destructor resistance according to Venn analysis, of which 4 of the DEPs were not annotated in GenBank. The remaining DEPs included $60 \mathrm{~S}$ acidic ribosomal protein $\mathrm{P} 2,60 \mathrm{~S}$ ribosomal protein L12, protein disulfide-isomerase, vitellogenin, endocuticle structural glycoprotein SgAbd- 2-like, odorant-binding protein 13 precursor, polyadenylate-binding protein 1-like, and troponin $\mathrm{C}$ type IIb. This is the first report to identify the function of polyadenylate-binding protein 1-like in bees. The 60S acidic ribosomal protein $\mathrm{P} 2$ and $60 \mathrm{~S}$ ribosomal protein L12 are structural synthesis proteins, and previous studies showed that the $60 \mathrm{~S}$ acidic ribosomal protein $\mathrm{P} 2$ is related to spatial memory (Zheng et al., 2010); however, there is not sufficient evidence to specifically link this protein to mite resistance. Vitellogenin was previously found to be related to climate adaptation, activated ovaries, reproductive competition, labor division, behavioral construct, and extended life; thus, it is also known as a pleiotropic protein (Amdam et al., 2009). However, its relationship with Varroa resistance and the mechanisms of mite resistance remains unknown. Troponin C type IIb protein expression differences between groups indicated that striated muscles within the heads of these bees show differences in contraction and relaxation upon Varroa infection. Some studies reported mites that appeared to be injured by the mandibles of worker bees (Peng et al., 1987; Rosenkranz et al., 1997). A. cerana worker bees (nurse-age worker bees) can also detect capped broods that are infested by $V$. destructor. In such cases, the bees open the infested cells to remove the mites, a phenomenon known as a hygienic or removal behavior (Peng et al., 1987; Boecking, 1992). Both of these behaviors require the use of muscles in the head, particularly the mandibles; thus, the differential expression of troponin indicates that this gene plays an important role in grooming and hygienic behaviors. Endocuticle structural glycoprotein SgAbd-2-like proteins may be involved in epidermis synthesis; Parker et al. (2012) found that chitin biosynthesis genes were associated with anti-mite traits in a proteomic study of the Western honeybee. Chitin and endocuticle structural glycoprotein are major components of the epidermis, indicating that the epidermis is the first barrier against bee mites. Many studies have suggested that bees with the greatest olfactory sensitivity generally initiate hygienic behavior first because they can detect and accurately discriminate between 
abnormal and normal broods at low stimulus intensities (Rothenbuhlder, 1964; Martin et al., 2001; Swanson et al., 2009). Additionally, obp13 has previously been shown to combine with oleic acid and similar compounds (Iovinella et al., 2011). obp13 may have specifically evolved to assist in identifying the smell of Varroa mites (Feng et al., 2014). In conclusion, our study on quantitative proteomic analysis by iTRAQ using the $A$. cerana transcriptome as reference identified 1532 proteins. GO enrichment analysis suggests that $\mathrm{C}^{+}$and $\mathrm{M}^{+}$responded differently to mite challenge. Pathway analysis revealed 1503 proteins associated with 239 pathways, with most annotated to metabolic pathways.

\section{Conflicts of interest}

The authors declare no conflict of interest.

\section{ACKNOWLEDGMENTS}

Research supported by the grant from the National Natural Science Foundation of China (\#31372382), the earmarked Fund for Modern Agro-Industry Technology Research System from the Ministry of Agriculture of China (\#CARS-45-SYZ6) and the Science \& Technology Planning Project of Jiangsu Province, China (\#SBE201230535).

\section{REFERENCES}

Amdam GV, Ihle KE and Page RE (2009). Regulation of honeybee worker (Apis mellifera) life histories by vitellogenin. Hormones, Brain and Behavior. 2nd edn. Vol. 2 (Pfaff DW, Arnold AP, Etgen AM, Fahrbach SE, et al., eds.). Academic Press, San Diego, 1003-1025.

Annoscia D, Del Piccolo F and Nazzi F (2012). How does the mite Varroa destructor kill the honeybee Apis mellifera? Alteration of cuticular hydrcarbons and water loss in infested honeybees. J. Insect. Physiol. 58: 1548-1555.

Arechavaleta-Velasco ME, Alcala-Escamilla K, Robles-Rios C, Tsuruda JM, et al. (2012). Fine-scale linkage mapping reveals a small set of candidate genes influencing honey bee grooming behavior in response to Varroa mites. PLoS One 7: e47269.

Ball BV and Allen MF (1988). The prevalence of pathogens in honey bee (Apis mellifera) colonies infested with the parasitic mite Varroa jacobsoni. Ann. Appl. Biol. 113: 237-244.

Boecking O (1992). Removal behavior of Apis mellifera towards sealed brood cells infested with Varroa jacobsoni: Techniques, extent and efficacity. Apidologie 23: 371-373.

Boot W, Tan N, Dien P, Vanhuan L, et al. (1997). Reproductive success of Varroa jacobsoni in brood of its original host, Apis cerana, in comparison to that of its new host, A. mellifera (Hymenoptera: Apidae). Bull. Entomol. Res. 87: 119-126.

Cornman RS, Tarpy DR, Chen Y, Jeffreys L, et al. (2012). Pathogen webs in collapsing honey bee colonies. PLoS One 7: e43562.

Feng M, Ramadan H, Han B, Fang Y, et al. (2014). Hemolymph proteome changes during worker brood development match the biological divergences between western honey bees (Apis mellifera) and eastern honey bees (Apis cerana). BMC Genomics 15: 563.

Fleige S and Pfaffl MW (2006). RNA integrity and the effect on the real-time qRT-PCR performance. Mol. Aspects Med. 27: $126-139$

Franck P, Coussy H, Le Conte Y, Solignac M, et al. (1999). Microsatellite analysis of sperm admixture in honeybee. Insect Mol. Biol. 8: 419-421.

Griffith D and Bowman C (1981). World distribution of the mites Varroa jacobsoni, a parasite of honeybee. Bee World 62: $154-163$

Guzman-Novoa E, Emsen B, Unger P, Espinosa-Montaño LG, et al. (2012). Genotypic variability and relationships between mite infestation levels, mite damage, grooming intensity, and removal of Varroa destructor mites in selected strains of worker honey bees (Apis mellifera L.). J. Invertebr. Pathol. 110: 314-320. 
Highfield AC, El Nagar A, Mackinder LC, Noël LM, et al. (2009). Deformed wing virus implicated in overwintering honeybee colony losses. Appl. Environ. Microbiol. 75: 7212-7220.

Iovinella I, Dani FR, Niccolini A, Sagona S, et al. (2011). Differential expression of odorant-binding proteins in the mandibular glands of the honey bee according to caste and age. J. Proteome Res. 10: 3439-3449.

Martin C, Provost E, Roux M, Bruchou, et al. (2001). Resistance of the honey bee, Apis mellifera to the acarian parasite Varroa destructor: behavioural and electroantennographic data. Physiol. Entomol. 26: 362-370.

Navajas M, Migeon A, Alaux C, Martin-Magniette M, et al. (2008). Differential gene expression of the honey bee Apis mellifera associated with Varroa destructor infection. BMC Genomics 9: 301.

Oldroyd BP (1999). Coevolution while you wait: Varroa jacobsoni, a new parasite of western honeybees. Trends Ecol. Evol. 14: 312-315.

Parker R, Guarna MM, Melathopoulos AP, Moon KM, et al. (2012). Correlation of proteome-wide changes with social immunity behaviors provides insight into resistance to the parasitic mite, Varroa destructor, in the honey bee (Apis mellifera). Genome Biol. 13: R81.

Peng YS, Fang Y, Xu S and Ge L (1987). The resistance mechanisms of the Asian honey bee, Apis cerana Fabr., to an ectoparasitic mite Varroa jacobsoni. J. Invert. Pathol. 49: 54-60.

Rath W and Drescher W (1990). Response of Apis Fabr. towards brood infested with Varroa jacobsoni outland infestation rate of colonies in Thailand. Apidologie 21: 311-321.

Rosenkranz P, Fries I, Boecking O and Stürmer M (1997). Damaged Varroa mites in the debris of honey bee (Apis mellifera L.) colonies with and without hatching brood. Apidologie 28: 427-437.

Rosenkranz P, Aumeier P and Ziegelmann B (2009). Biology and control of Varroa destructor. J. Invertebr. Pathol. 103 (Suppl 1): S96-S119.

Rothenbuhler WC (1964). Behaviour genetics of nest cleaning in honey bees. I. Responses of four inbred lines to disease killed brood. Anim. Behav. 5: 578-583.

Sammataro D, Gerson U and Needham G (2000). Parasitic mites of honey bees: life history, implications, and impact. Annu. Rev. Entomol. 45: 519-548.

Sun J, Mu H, Zhang H, Chandramouli KH, et al. (2013). Understanding the regulation of estivation in a freshwater snail through iTRAQ-based comparative proteomics. J. Proteome Res. 12: 5271-5280.

Swanson JA, Torto B, Kells SA, Mesce KA, et al. (2009). Odorants that induce hygienic behavior in honeybees: identification of volatile compounds in chalkbrood-infected honeybee larvae. J. Chem. Ecol. 35: 1108-1116.

Tan K and Yu Y (2002). Resistance of mites Varroa jacobsoni of Apis cerana colonies. Apic. China 53: 10-12.

Tsuruda JM, Harris JW, Bourgeois L, Danka RG, et al. (2012). High-resolution linkage analyses to identify genes that influence Varroa sensitive hygiene behavior in honey bees. PLoS One 7: e48276.

van Engelsdorp D, Hayes J Jr, Underwood RM and Pettis J (2008). A survey of honey bee colony losses in the U.S., fall 2007 to spring 2008. PLoS One 3: e4071.

Warrit N and Lekprayoon C (2011). Honeybees of Asia (Hepburn RH and Radloff SE, eds.). Springer, Berlin, Germany.

Winston ML (1987). The biology of the honey bee. Harvard University Press, Boston.

Zheng JF, Sun CY, Sun LC, Yuan XM, et al. (2010). A proteomic survey of spatial memory related proteins in mice. Acta Chim. Sin. 68: 996-1002.

Zhou T (2005). The biological characteristics and the natural distribution of Varroa destructor in China. Doctoral thesis, China Agricultural University, Beijing, China. 